\title{
Molecular Dynamics Simulation of Tensile Behavior on Ceramic Particles Reinforced Aluminum Matrix Nanocomposites
}

\author{
Heng Gu ${ }^{1}$, , Jiao Jiao Wang ${ }^{2}$, Zhongwei $\mathrm{Li}^{3}$ \\ ${ }^{1}$ Rexa, Inc. West Bridgewater, MA, USA \\ ${ }^{2}$ School of Materials Science and Engineering, East China University of Science and Technology, Shanghai, China \\ ${ }^{3}$ Department of Naval Architecture and Marine Engineering, University of New Orleans, New Orleans, LA, USA \\ Email address: \\ hgcare@gmail.com (Heng Gu) \\ ${ }^{*}$ Corresponding author
}

\section{To cite this article:}

Heng Gu, Jiao Jiao Wang, Zhongwei Li. Molecular Dynamics Simulation of Tensile Behavior on Ceramic Particles Reinforced Aluminum Matrix Nanocomposites. International Journal of Materials Science and Applications. Vol. 5, No. 3, 2016, pp. 151-159.

doi: 10.11648/j.ijmsa.20160503.16

Received: June 10, 2016; Accepted: July 4, 2016; Published: July 7, 2016

\begin{abstract}
The mechanical properties and interfacial structures for aluminum matrix composites reinforced by nanometer-sized SiC- $\beta$ particles has been studied using molecular dynamics (MD) simulation. The modified embedded atom methods, was implemented to describe the atomic interactions. The molecular model undergoes an annealing MD simulation from $300 \mathrm{~K}$ to $1000 \mathrm{~K}$ to reach its minimum energy point. Tensile tests were performed with periodic boundary conditions. The stress-strain relationship has been studied and elastic constants were predicted as well. The results were compared with those given by continuum-based finite element analysis (FEA) together with the experimental data available in the literatures. It showed that both the elastic modulus and yield stress were further strengthened due to the presence of the nano-particles. Also, it was found that the existing $\mathrm{SiC}$ nano-particles have an effect on the initial arrangement of $\mathrm{Al}$ atoms in such a manner: $\mathrm{Al}$ atoms were inclined to aggregate around the particle surface. Aluminum concentrations were also observed inside the SiC particles close to the surface. The depth of hybridization is uniform and planar.
\end{abstract}

Keywords: Molecular Dynamics, Aluminum Matrix Composites, Silicon Carbide Nano-particles

\section{Introduction}

In the past decades, metal matrix composites (MMCs) have emerged as a class of materials capable of advanced structural, aerospace, automotive, electronic, thermal management, and wear applications $[1-2,3]$. The selective matrix alloys, such as Aluminium [4, 5], have been predominantly employed for the production of MMCs reinforced by nanoparticles due to the fact that it is superior in terms of improved mechanical and thermal properties (including specific strength and modulus, elevated temperature stability, higher thermal conductivity, and controlled coefficient of thermal expansion) $[6,7,8]$.

The large surface-volume ratio of the nano-sized inclusions, significant improvements in the material properties have been observed at the nanoscale and has become active in recent years $[9,10,11,12]$. Such mechanical property improvements have resulted in major interest in nanocomposite materials in numerous automotive and general industrial applications [13]. These include potential for utilization as mirror housings on various vehicle types, door handles, engine covers and intake manifolds and timing belt covers. More general applications currently being considered include usage as impellers and blades for vacuum cleaners, aircraft parts, power tool housings, mower hoods and covers for portable electronics such as mobile phones and pagers $[14,15,16]$. 


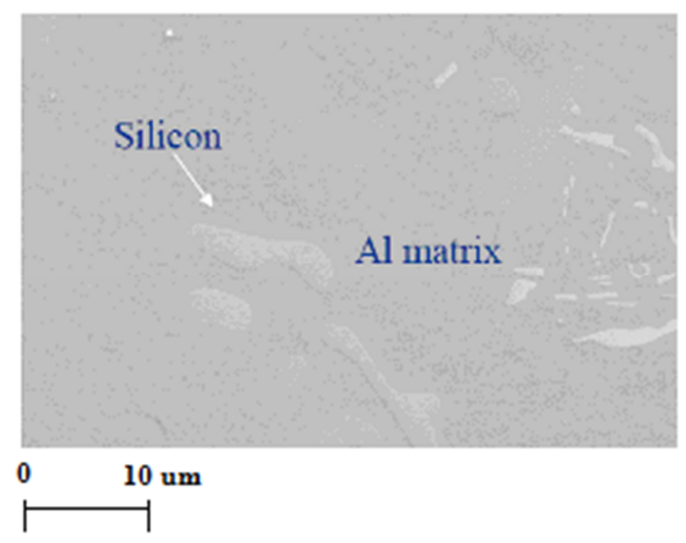

(a)

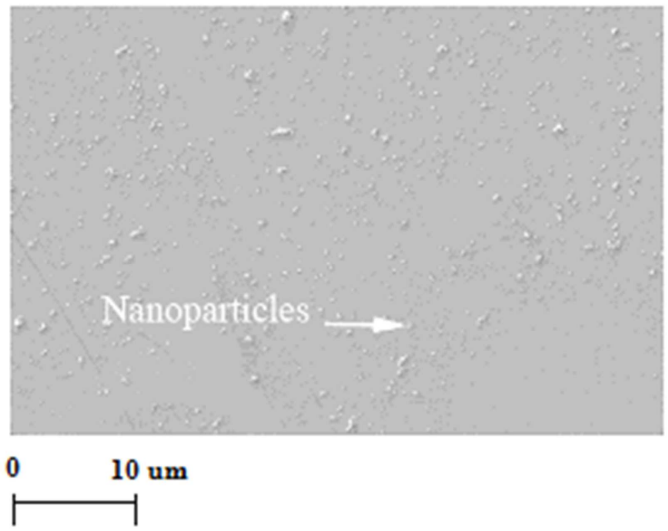

(b)

Figure 1. Scanning Electron Microscopy (SEM) micrograph: (a) No SiC with 60 mins ultrasonic processing, (b) $1.0 \% \mathrm{SiC}$ (weight) with 60mins ultrasonic processing.

Although substantial technical challenges remain in fabrication, several methods have been developed, e.g. Yang and $\mathrm{Li}$ [17] presented an inexpensive fabrication method for achieving uniform distribution of nano-sized SiC particles in molten aluminum alloy A356, employing the ultrasonic nonlinear effects, known as transit cavitation and acoustic streaming [18]. A total of $20 \%$ hardness increasing was measured with a 2.0 vol\% nanoparticle addition in aluminum alloy. Gierlotka et al. [19] used high-pressure infiltration methods to synthesize metal-ceramic nanocomposites: this process is done in a toroid high pressure $(7.7 \mathrm{GPa})$ and high temperature (up to $20000^{\circ} \mathrm{C}$ ). The nanoporous matrix is prepared by compacting nanopowders of high-hardness materials such as $\mathrm{Al}_{2} \mathrm{O}_{3}, \mathrm{SiC}$, or diamond et al. [20, 21, 22]. The infiltrating material can be any substance with the melting temperature (at a given pressure) below the processing temperature. When the infiltrant melts the pressure forces it to fill the pores in the matrix. The resulting composite contains a continuous network of solidified injected material with embedded grains of the ceramic powder [23, 24].

Due to the small length scale, neither classical continuum mechanics nor traditional numerical methods, such as FEA, are sufficient in predicting the material properties [25, 26, 27].
The atomistic interaction between a ceramics and a metal is of great significance in the improvement of the bulk material properties of the composites. Traditional numerical methods do not take this into account. Molecular dynamics (MD) could well describe the atomistic interaction between two condensed-phase materials and provides a proper numerical approach to characterization of nanocomposites [28]. However, the high computational cost associated with large-scale MD simulations limits its use beyond the nanoscale whereas the use of micromechanical homogenization techniques in a multiscale framework can lead to the propagation of large errors across length scales [29]. Therefore, efforts have been made to maximize computational efficiency and maintain high accuracy while investigating the material behavior at the micro-, meso and macro-scales [30, 31, 32]. A significant amount of research has been conducted in this field to develop a multiscale model to characterize material properties [33, 34]. Techniques that rely on discrete material distribution and simplified analyses have been developed. Underhill and Doyle [35] developed a spring-bead model in which each bead represents a large segment of molecular chains, to model the mechanical response of a polymer. Furthermore, Zhang et al. [36, 37] developed a spring-bead based cross linked network model which can simulate larger polymer chains and microstructures. In Zhang's work, MD simulation was implemented to provide necessary information to construct the model. The network model was found to be more accurate than micromechanical approximation techniques for characterizing amorphous materials. This result indicates the MD simulation is important in development of multiscale model of composite materials.

In this work, a molecular model is developed, which is characterized by a representative volume element (RVE) of Al matrix with a silicon carbide $(\mathrm{SiC})$ particle embedded inside. The interface between the $\mathrm{Al}$ matrix and $\mathrm{SiC}$ particle was built up in a proper way to avoid the defects produced by the misfit of the lattice constants in the initial structure. The nanocomposite model was built at a relatively high temperature $(1000 \mathrm{~K})$ at which the aluminum is in the liquid state, which was cooled down to room temperature (300 K). The calculated results have proved that there is an apparent enhancement in material properties including tensile strength and toughness. The morphological features were also examined: the aluminum atoms in the neighborhood of the particle align with the shape of the inclusion. Al atoms are easy to be captured to cluster around carbon-rich sites, so hybridization could be observed beneath the surface of $\mathrm{SiC}$ within a certain depth.

\section{Basic Theories in Molecular Dynamics}

Calculations in molecular dynamics (MD) are based on the energy minimization. An appropriate interatomic potential plays a key role in MD simulations. The potential law between atoms in this study obeys Lennard-Jones potential as follows [38]. 


$$
\phi(r)=\varepsilon\left[\left(\frac{\sigma}{r}\right)^{12}-\left(\frac{\sigma}{r}\right)^{6}\right]
$$

Although this is an approximate potential, it can character the interactions between closed aligned atoms, which is a strong repulsive short range interaction, namely a long range van der Waals attraction. The mathematical form shown in Eq. 1 is simple, but it is actually more realistic in its treatment of long range interactions, than the Morse function. However, it only deals with a single pair of atoms. For further-step accurate simulations, many body interactions will be applied. This requires a through understanding of the influence of the local electronic density. In the recent few decades, lots of progress has been made in identifying multi-atom potentials. The most popular theories are: the embedded atom model (EAM), the finnis-Sinclair potentials and the tight-binding potential. Based on different approaches, these models are shown to be equivalent from the mathematical point of view. In this work, the modified embedded atom method (MEAM) [39] will be employed to describe the intermetallic and metal-ceramic interactions as well as the bonding in the SiC- $\beta$ particle. It has been shown that MEAM matches well with empirical and ab-initio calculations [38, 40]. In the MEAM the total energy $E$ of the system is as the sum of defined energy atoms, with each energy contributions from an embedding function $\mathrm{F}$ connecting to the electron density and a pair potential $\Phi$ :

$$
\begin{aligned}
& E=\sum_{i}\left[F\left(\bar{\rho}_{i}\right)+\frac{1}{2} \sum_{j(\neq i)} \phi\left(R_{i j}\right),\right. \\
& \text { where, } F\left(\bar{\rho}_{i}\right)=A E_{c} \frac{\bar{\rho}_{i}}{\bar{\rho}^{o}} \ln \frac{\bar{\rho}_{i}}{\bar{\rho}^{o}}
\end{aligned}
$$

Here A is a constant. The pair potential, $\phi$, only depends on the distance between atoms $i$ and $j, R_{i j}=\left|\vec{r}_{i}-\vec{r}_{j}\right|$. Ec is the cohesive energy. $\bar{\rho}^{o}$ is a reference electron density. The actual angular dependence of the potential is embedded in the definition of $\bar{\rho}_{i}$. which represents the electron density at atomic site $i$. The electron density is defined as:

$$
\bar{\rho}_{i}=\bar{\rho}^{(o)} \sqrt{1+\Gamma_{i}}, \Gamma_{i}=\sum_{h=1}^{3} t^{(h)}\left(\frac{\rho_{i}^{(h)}}{\rho_{i}^{(o)}}\right)^{2}
$$

where $\mathrm{t}$ is an adjustable parameter which weights the directional dependence, $\rho_{i}^{(o)}$ is a spherically symmetric term, $\rho_{i}^{(h)}(\mathrm{h}=1,2,3)$ is the angular dependent terms of the electron density as

$$
\left(\rho_{i}^{(h)}\right)^{2}=\sum_{j \neq i} \rho_{i}^{a(o)}\left(R_{i j}\right)
$$

$$
\begin{gathered}
\left(\rho_{i}^{(1)}\right)^{2}=\sum_{\alpha}\left[\sum_{j \neq i} \rho_{i}^{a(1)}\left(R_{i j}\right) \frac{R_{i j}^{\alpha}}{R_{i j}}\right]^{2}, \\
\left(\rho_{i}^{(2)}\right)^{2}=\sum_{\alpha, \beta}\left[\sum_{j \neq i} \rho_{i}^{a(2)}\left(R_{i j}\right) \frac{R_{i j}^{\alpha} R_{i j}^{\beta}}{R_{i j}^{2}}\right]^{2}-\frac{1}{3} \sum_{j \neq i}\left[\rho_{i}^{a(2)}\left(R_{i j}\right)\right]^{2}, \\
\text { where, } \rho_{i}^{\alpha(h)}(R)=\exp \left[-\beta^{(h)}\left(R / r_{e}-1\right)\right]
\end{gathered}
$$

is the electron density from a neighboring atom at a distance $\mathrm{R}$ from the atom of interest. The $\alpha, \beta$ and $\gamma$ variables are summed over the three directional components of the distance vector between atoms $i$ and $j$. [38]

\section{Model of Molecular Dynamics Simulation}

As shown in Fig. 2 (a), pure aluminum is characterized by face-centered cubic (FCC) periodic crystal structure. Silicon carbide (Fig. 2 (b) has the same FCC crystal structure, but in the compound, each silicon atom is bonded to four carbon atoms. The covalent bonds between silicon and carbon are very strong. Thus the bulk silicon carbide presents high stiffness. As shown in Fig. 3, the model consists of a cube of aluminum atoms with a center-placed spherical inclusion of silicon carbide (red part). The edge length of the cube is $4.050 \mathrm{~nm}$ and the diameter of the sphere equals $1.305 \mathrm{~nm}$.

The molecular model containing 4,719 atoms was set up and schematically shown in Fig. 4. The aluminum was aligned in a matrix with a block SiC- $\beta$ embedded inside to ensure both materials have common crystalline orientation. Each inner surface of the aluminum block is parallel to the corresponding outer surface of the sub-block. The interface geometries were created by assigning a proper value to the interfacial gap. This interface separation value $t$ was chosen to be $1.575 \AA$, at which the lattice mismatch and the influence of residual strain in the initial model so that the whole structure turns out to be periodic.

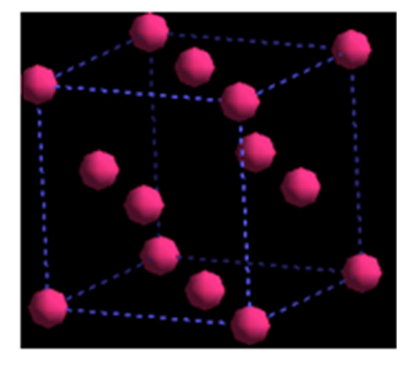

(a)

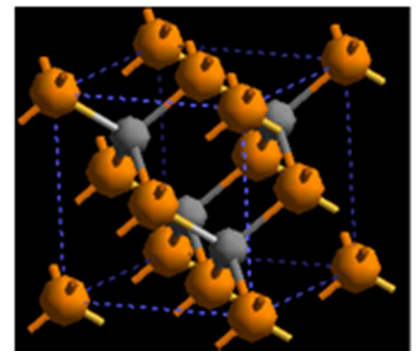

(b)
Figure 2. Crystal structure: (a) pure aluminum: lattice constant $=4.05 \ddot{A}$ Cell angle $\alpha=\beta=\gamma=90$ o.

The $\mathrm{Si}$ and $\mathrm{C}$ atoms were placed within a spherical region whose geometric center coincides with that of the blocks. The radius of the sphere, $r$, was set to be $6.525 \AA$, which is equal to half of the edge length of the sub-block. The redundant Si and 
$\mathrm{C}$ atoms outside the sphere (the grey part) were removed. Afterwards, a second spherical surface, sharing the same geometric center and with a radius of $8.10 \AA(\mathrm{r}+\mathrm{t})$, was created. The vacuum space outside the surface was filled in with aluminum atomsl the atoms are displayed with their van der Waals radius, and each the nanoparticle can be approximated to be a sphere, with the diameter of $1.305 \mathrm{~nm}$.

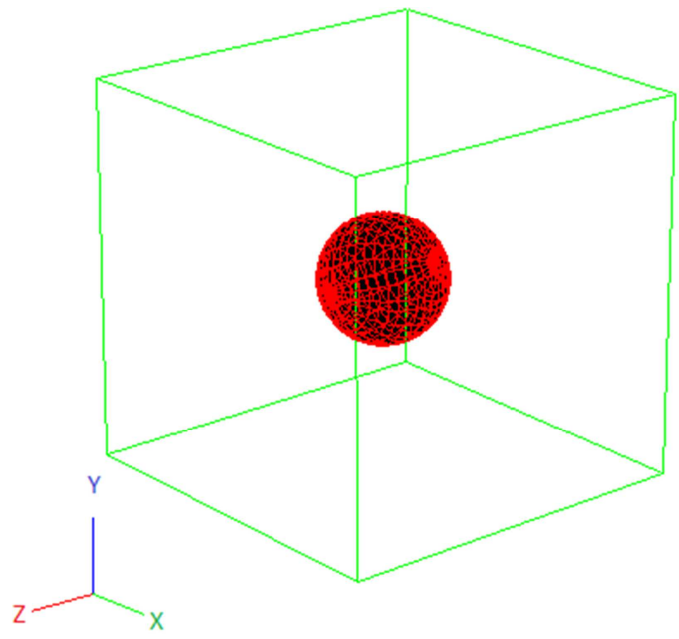

Figure 3. Representative Volume Element (RVE).

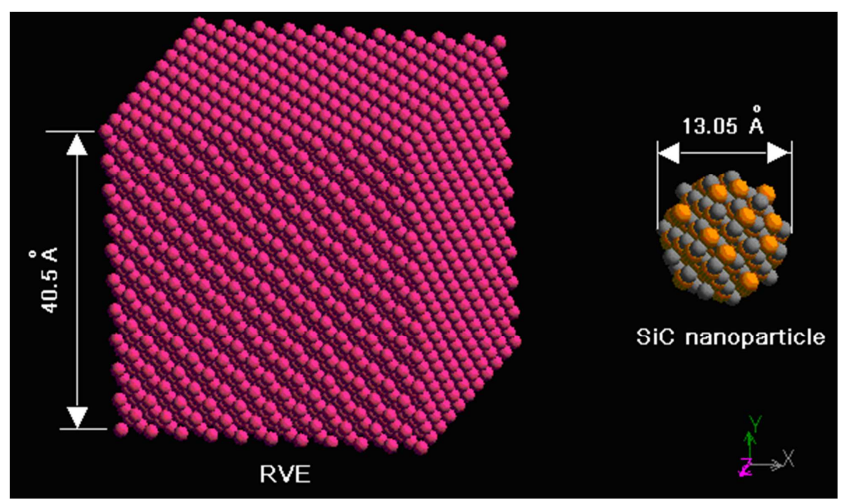

Figure 4. RVE with dimensions (Aluminum matrix and SiC nanoparticle).

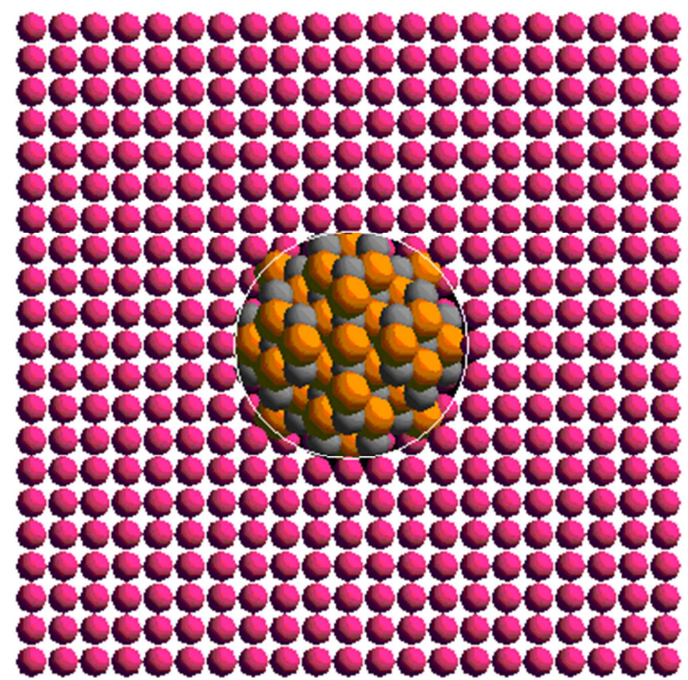

Figure 5. Molecular Model of Al-SiC nanocomposites.

\section{Energy Minimization}

Molecular mechanics consider the molecule to be a collection of atoms held together by simple elastic or harmonic forces. The MD simulation uses the parameters of force fields, a mathematical expressions employing a combination of internal coordinates and bond terms (bond distances, bond angles, torsions, etc.), to describe the dependence of the energy of a molecule on the coordinates of the atoms in the molecule, and non-bond terms to describe the van der Waals and electrostatic interactions between atoms.

For condense-phase materials such as ceramics and metals considered here, the force field given by the Condensed-phase Optimized Molecular Potential (COMPASS) was used, whose development focuses on high accuracy.

The initial temperature of the simulation box was set to be 0 $\mathrm{K}$ using the theory of molecular mechanics. After this calculation the system was equilibrated. Since the minimization methods can only optimize the atomistic model to the closest local minimum point (Fig. 7) [17], so this state of equilibrium largely depends on the starting structure, from where the system energy falls to a local minimum point.

The most straightforward way to find the global minimum is to do a systematic conformational search. However, it is time-consuming and infeasible for systems with large number of molecules. As a result, simulated annealing is commonly used to find the global minimum. In the simulated annealing procedure, the simulation commences at a high temperature where most attempted (moves) are accepted and the temperature is then slowly reduced. The transition probability is reduced in concert so that the average energy of the sampled points in the space also diminishes. At the conclusion of the annealing, the resulting point will, in general, be near the global energy minimum for the system.

The atoms were initially assigned with velocities following a Maxwell-Boltzmann distribution around the target temperature $(300 \mathrm{~K})$. Then the interatomic potential (MEAM), a dynamics simulation was performed in our model for 0.001 ps, with the isothermal canonical ensemble NVT (constant volume-constant temperature) using Nosé-Hoover method as thermostat to control the temperature. The calculation started at an initial temperature of $300 \mathrm{~K}$ which would be raised up to the mid-cycle temperature $1100 \mathrm{~K}$ and then cooled down to $300 \mathrm{~K}$ again. The temperature increment was $50 \mathrm{~K}$. There were 500 time steps in maximum for integration. The model underwent 15 cycles.

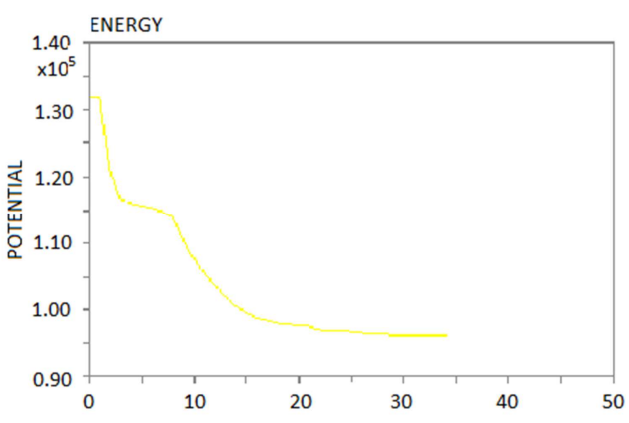

(a) 


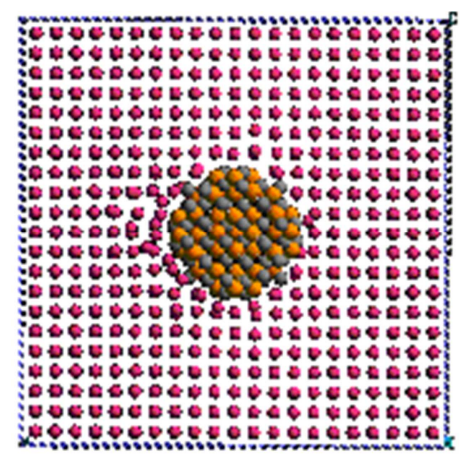

(b)

Figure 6. Energy Minimization at $0 \mathrm{~K}$ : (a) total potential energy of the system, (b) energy-minimized configuration.

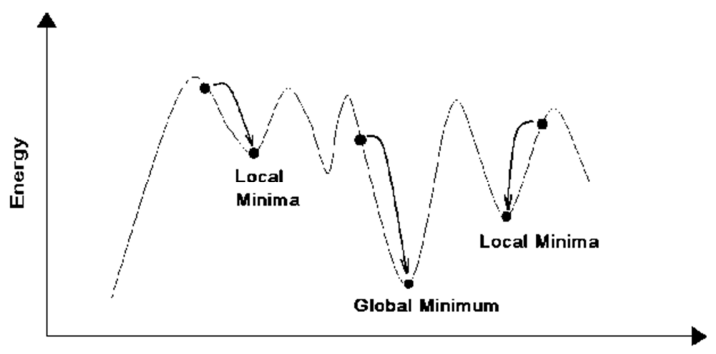

Figure 7. Local Minima and Global Minimum

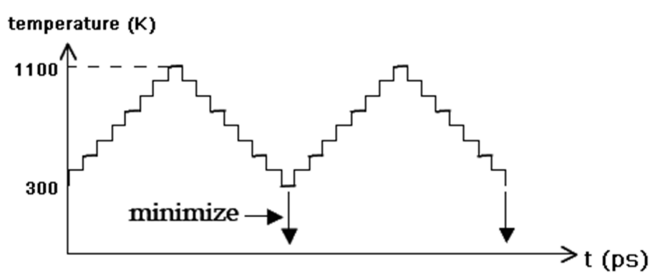

Figure 8. Simulated annealing cycles

\section{Results and discussion}

\subsection{Interfacial Morphology}

Interfacial structure and chemistry are important factors influencing the properties of material. The final configuration obtained in this work is shown in Fig. 9 (a). In the far field of the matrix, the atom arrangement is still in a good agreement with crystal structure of pure aluminum. It is clearly shown that the morphology of atoms in the center of the SiC- $\beta$ nanosphere do not change too much due to the strong bonds between silicon and carbon atoms, but in its neighboring region to the aluminum matrix original lattice constants are severely distorted. The atoms are clustered and follow the structure of the particle. This actually increases the effective size of the nanoparticle. In order to study the influence of size effect, the same MD calculation was performed on a larger system with particle of $2.18 \mathrm{~nm}$ in diameter (Fig. 9(b)). This result is similar to that in Fig. 9(a), with clearer interfacial layer observed.

The chemical composition of the $\mathrm{Al} / \mathrm{SiC}$ interfacial structure using two different annealing conditions has been studied by Arsennalt R. J. et al [41]. At a higher temperature above $700^{\circ} \mathrm{C}, \mathrm{Al}_{4} \mathrm{C}_{3}$ formed rapidly to form a planer and clean interfacial layer. The formation rate of $\mathrm{Al}_{4} \mathrm{C}_{3}$ is quite fast so that the diffusion of $\mathrm{Al}$ into $\mathrm{SiC}$ is prevented. Bermudez $\mathrm{V}$. [42] investigate the the physical and electronic structure of the interface between $\mathrm{Al}$ and $\mathrm{SiC}$, employing spectroscopic methods. His results revealed that the aluminum atoms form islands randomly distributed over the surface of $\mathrm{SiC}$ particle and $\mathrm{Al}$ aggregates at Carbon-rich points and reacts with Carbon to form $\mathrm{Al}_{4} \mathrm{C}_{3}$. Theoretical quantum mechanics studies were also carried out: Arsenault R. J., Li S. and Jena P. [43] used the intermediate neglect of differential overlap (INDO) method to study adhesion at $\mathrm{SiC} / \mathrm{Al}$ interfaces and proved that the bond strength between $\mathrm{SiC}$ and $\mathrm{Al}$ could be 1.5 times stronger than the bond between Al and Al. Rao and Jena [44] performed a self-consistent quantum mechanical calculation to study the Al-Al, Al-Si, Al-C interactions using unrestricted Hartree-Fock theory. Their results show that the binding energy of Al-C is significantly higher than that of Al-Al and $\mathrm{Al}-\mathrm{Si}$. When an interface is formed between $\mathrm{Al}$ and $\mathrm{SiC}, \mathrm{Al}$ will be bonded with the exposed $\mathrm{C}$ atoms, which accounts for the annealing study in [45].

As shown in Fig. 6, after minimizing the energy at $0 \mathrm{~K}$, the $\mathrm{SiC}$ phase looks chemically stable. No hybridization has been observed, so we did not obtain any evidence that diffusions or penetrations of $\mathrm{Al}$ atoms into $\mathrm{SiC}$ compound took place. However, in Fig. 9, the $\mathrm{Al}$ atoms became clustered around the sphere after annealing above $1000 \mathrm{~K}$, forming a layer of $\mathrm{Al}$ islands distributed randomly over the surface of the $\mathrm{SiC}$ particle. The $\mathrm{Al}$ layer is non-uniform but turns out to be patching on the $\mathrm{SiC}$ surface. It is noticed that $\mathrm{Al}$ atoms are more likely to deposit around the exposed $\mathrm{C}$ atoms. Former quantum chemical calculations well explained it: the Al-C interaction is much stronger than $\mathrm{Al}-\mathrm{Al}, \mathrm{Al}-\mathrm{Si}$, so $\mathrm{Al}$ atoms are more possible to be captured by $\mathrm{C}$. The $\mathrm{Al}$ concentration of about $50 \%$ of the $\mathrm{Al}$ matrix is seen to be present $2-3 \AA$ deep into the $\mathrm{SiC}$. The hybridization band of $\mathrm{Al}$ and $\mathrm{SiC}$ is quite neat and of uniform thickness, since when it goes beyond $3 \AA$ from the interface into the particle, the $\mathrm{Al}$ concentration falls sharply to very small magnitude close to 0 . This matches the experimental result that the formation of a planar $\mathrm{Al}_{4} \mathrm{C}_{3}$ layer prevents the diffusion of $\mathrm{Al}$ into $\mathrm{SiC}$ as well as the dissolving of $\mathrm{SiC}$ [46]. As shown in Fig. 10, Si and $\mathrm{C}$ concentrations diminish very quickly when it goes out of the interface.

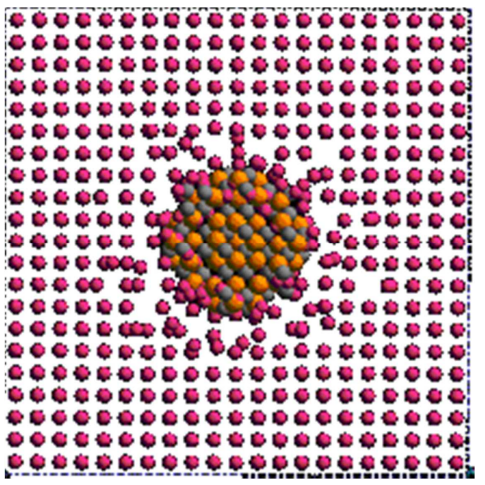

(a) 


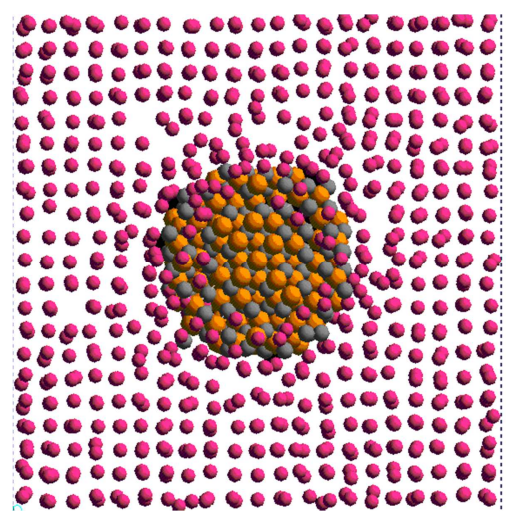

(b)

Figure 9. Final Configurations: (a) Nanoparticle diameter $=1.305 \mathrm{~nm}$; (b) Nanoparticle diameter $=2.180 \mathrm{~nm}$.

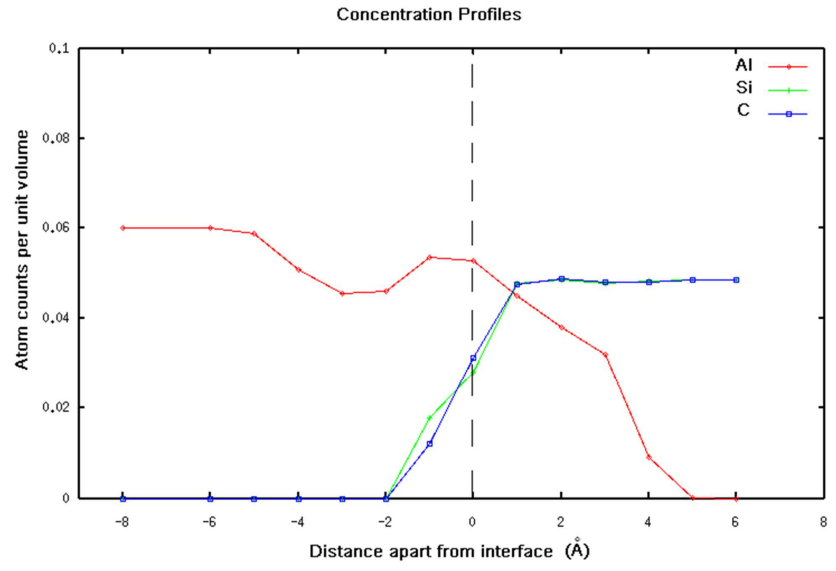

Figure 10. Concentration profile (Nanoparticle diameter $=1.305 \mathrm{~nm}$ ).

\subsection{Elastic Constants}

Assigning boundary conditions to the periodic model, a simulated tension test was carried out. By fixing the $\mathrm{x}=0$ surface, a strain increment of $0.1 \%$ is applied to another surface which is perpendicular to $\mathrm{x}$-axis at $300 \mathrm{~K}$. Then the system is relaxed by minimizing the energy. There are various theories for the calculation of mechanical properties. The bulk modulus of the metals and alloys was calculated by using the method proposed in [47]. The elastic constants were calculated at the experimental lattice constants from the difference in the total energies of the distorted and undistorted lattices. In Hu's work, the elastic constants of Gold Nanorods Produced are determined by Seed Mediated Growth [48]. The methodology is to use a single-point energy calculation to obtain the second derivatives of the lattice energy with respect to the lattice parameters and the atomic coordinates. The energy expression:

$$
U=U_{0}+\frac{\partial U}{\partial \varepsilon_{i j}} \varepsilon_{i j}+\frac{1}{2} \frac{\partial U^{2}}{\partial \varepsilon_{i j} \partial \varepsilon_{k l}}+\ldots
$$

where $\mathrm{U}_{\mathrm{o}}$ is the equilibrium energy and $\mathcal{E}_{i i}$ are the strain. When the system is at an energy minimum (that is, all first-order derivatives of the lattice energy are zero), the second-order derivative term can be used to calculate the components $\mathrm{C}_{\mathrm{ijkl}}$ of the stiffness tensor

$$
C_{i j k l}=\frac{\partial U^{2}}{\partial \varepsilon_{i j} \partial \varepsilon_{k l}}, C_{k l i j}=C_{i j l k}=C_{j i k l}
$$

A finite element analysis was also performed using the classical continuum theory by assuming the composites simply consist of two phases (the interfacial layer would not be taken into account). The effective volume fraction of the $\mathrm{SiC}$ particle was taken to be identical to that of the molecular RVE. The FE analysis used the same boundary conditions and dimensions as those for the MD model. Both $\mathrm{Al}$ and $\mathrm{Al} 6061$ are used for the ductile matrix: $\mathrm{E}=68.0 \mathrm{GPa}, v=0.33$ for pure $\mathrm{Al} ; \mathrm{E}=68.3 \mathrm{GPa}$, $v=0.33$ for Al6061; $\mathrm{E}=401 \mathrm{GPa}, v=0.22$ For silicon carbide. The stress-strain relations obtained from MD simulation and FE analyses are compared (Fig. 11 and Fig. 12).

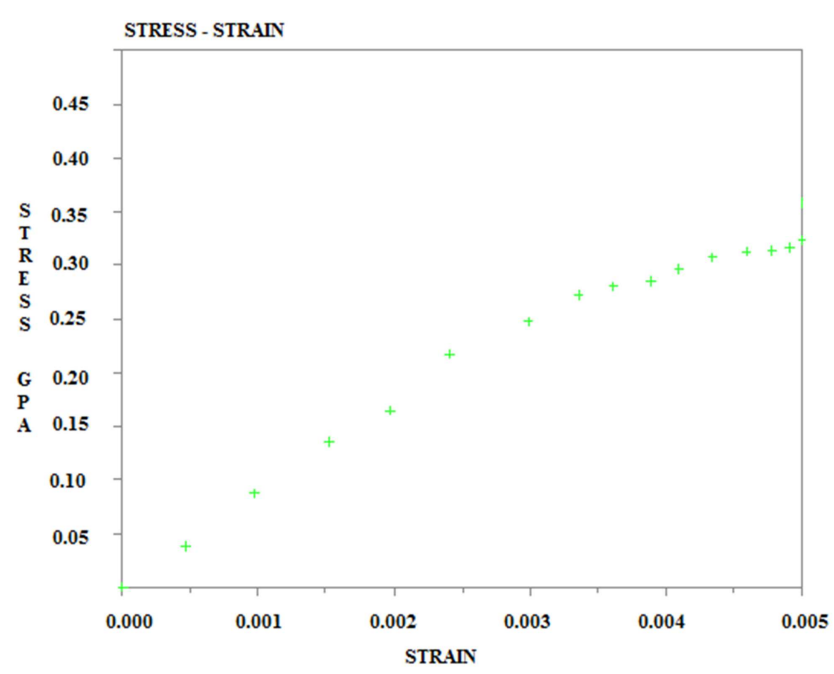

Figure 11. Plotted stress-strain curve.

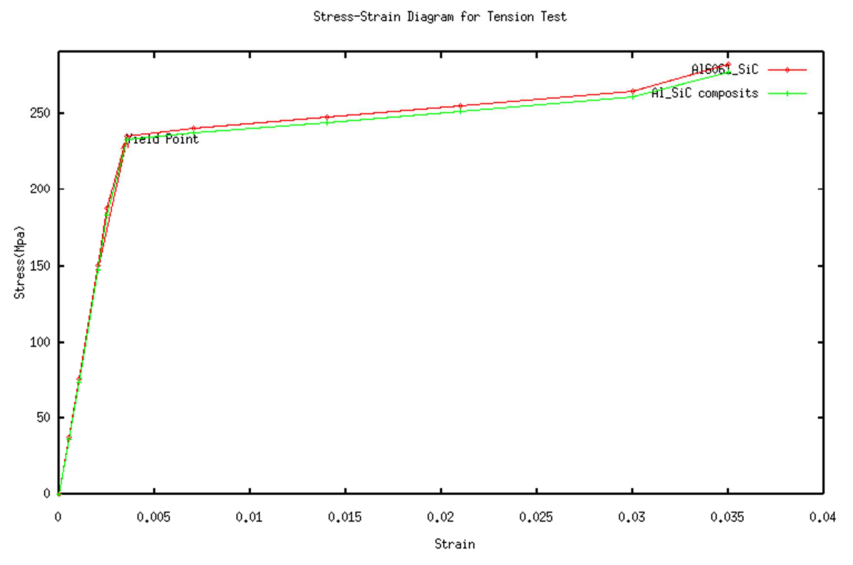

Figure 12. Stress-strain curves from FEA.

Table 1. Molecular Dynamics Results.

\begin{tabular}{ll}
\hline Young Modulus (GPa) & Poisson Ratios \\
\hline $\mathrm{E}_{\mathrm{x}}=82.62$ & $v_{\mathrm{xy}}=0.30 \quad v_{\mathrm{xz}}=0.31$ \\
$\mathrm{E}_{\mathrm{y}}=81.29$ & $v_{\mathrm{yx}}=0.30 \quad v_{\mathrm{yz}}=0.31$ \\
$\mathrm{E}_{\mathrm{z}}=82.93$ & $v_{\mathrm{zx}}=0.31 \quad v_{\mathrm{zy}}=0.31$ \\
Yield Strength & $\sigma_{\mathrm{Y}}=275 \mathrm{MPa}$ \\
\hline
\end{tabular}


Table 2. Finite Element Analysis Results.

\begin{tabular}{ll}
\hline Young Modulus (GPa) & Yield Strength \\
\hline $\mathrm{E}=75.42 \mathrm{GPa}$ & $\sigma_{\mathrm{Y}}=243 \mathrm{MPa}$ \\
\hline
\end{tabular}

The results indicate that the Young's moduli estimated based on MD simulations are $8-10 \%$ higher than the results obtained from FEA. The yield strength from MD is $15 \%$ higher than that from FEA. This MD results match well with the reported results in which a $2.0 \mathrm{vol} \%$ nanoparticle addition in aluminum alloy results in a $20 \%$ higher stiffness [17]. Hardening occurs when the strain is higher than $4.0 \%$. The stress is raised up to $290 \mathrm{MPa}$. The simplified FE analysis in which there existed only two phases does not take into account of the molecular structure of the metal/ceramic interface. There is high stress concentration at the interface between $\mathrm{Al}$ and $\mathrm{SiC}$. The response of the composites to the applied loading is also a function of the spatial distribution of the inclusions, given that the volume fraction does not change. The elastic constants from molecular dynamics present a small anisotropy in the orthogonal directions. This is mainly due to the geometrical imperfection of the spherical $\mathrm{SiC}$ nanoparticle induced by the approximate discretization: the particle surface is not perfectly spherical and its radius is only a nominal value. FE analysis cannot predict the elastic constants accurately because the continuum model regards the material as uniform, while the density changes along the radial distance from the interface due to the rearrangement of the atoms in the matrix and the mass conservation. The mechanical reinforcement of the composites revealed in the current MD study can be explained by the strong chemical bonds between aluminum and carbon atoms, as illustrated in previous experiments and quantum mechanics calculations [49]. Surely, the calculation was based on the assumption that there is no defect in the material and the inclusion is perfectly bonded to the matrix in reality.

\section{Conclusion}

In this work, molecular dynamics simulations have been performed on an Al-SiC nano-composite system using the interatomic potential. By employing annealing technique, the system reach an equilibrium state at the room temperature. Based on the principle of energy minimization, the elastic constants for the composites were estimated and the $\mathrm{SiC} / \mathrm{Al}$ interfacial structure was also investigated. The results reveal that the strong bonding energy between aluminum and carbon can significantly strengthen the composites and an effective interface can be obtained. The results match well with existing experiments and FE simulations.

\section{Acknowledgements}

The thoughtful discussion with Dr. J. Zhang and his advices are gratefully appreciated. The authors also wish to thank Dr. $\mathrm{K}$. Li for his contributions and Dr. X. Li for providing experimental data. The computations are supported by supercomputer facility and Laboratory of Molecular
Simulation (LMS) at Texas A\&M University, which are thankfully acknowledged.

\section{References}

[1] Wu Y, Qiao X, Fan X, Zhang X, Cui S, Wan J. Facile synthesis of monodisperse $\mathrm{Cu}_{3} \mathrm{SbSe}_{4}$ nanoparticles and thermoelectric performance of $\mathrm{Cu}_{3} \mathrm{SbSe}_{4}$ nanoparticle-based materials. Journal of Nanoparticle Research. 2015 Jul 1; 17(7): 1-7.

[2] Feng YC, Cao GJ, Fan GH, Wang LP, Geng L. Preparation and Characteristics of Al Matrix Composites Reinforced with $\mathrm{ZnWO}_{4}$ Coated $\left(\mathrm{WO}_{3} \mathrm{p}+\mathrm{ABOw}\right)$ Hybrid Reinforcements. JOM. 2013 Feb 1; 65(2): 278-83.

[3] Xu X, Hong YK, Park J, Lee W, Lane AM. Ex situ synthesis of magnetically exchange coupled $\mathrm{SrFe}_{12} \mathrm{O}_{19} / \mathrm{Fe}-\mathrm{Co}$ composites. AIP Advances. 2016 May 1; 6(5): 056026.

[4] Wang J, Brabazon D, Phillion AB, Lu G. An innovative two-stage reheating process for wrought aluminum alloy during thixoforming. Metallurgical and Materials Transactions A. 2015 Sep 1; 46(9): 4191-201.

[5] Wang JJ, Shang SZ, Lu GM, Yu JG. Research on the constitutive relationship of semi-solid ZL 201 alloy. Cailiao Kexue Yu Gongyi. 2012 Sep; 20(5): 127-31.

[6] Li XP, Liu CY, Ma MZ, Liu RP. Microstructures and mechanical properties of AA6061-SiC composites prepared through spark plasma sintering and hot rolling. Materials Science and Engineering: A. 2016 Jan 5; 650: 139-44.

[7] Liu Y, Huang J, Yang B, Sumpter BG, Qiao R. Duality of the interfacial thermal conductance in graphene-based nanocomposites. Carbon. 2014 Aug 31; 75: 169-77.

[8] Liu CY, Jing R, Wang Q, Zhang B, Jia YZ, Ma MZ, Liu RP. Fabrication of $\mathrm{Al} / \mathrm{Al}_{3} \mathrm{Mg}_{2}$ composite by vacuum annealing and accumulative roll-bonding process. Materials Science and Engineering: A. 2012 Dec 15; 558: 510-6.

[9] Xu Q, Wan Y, Hu TS, Liu TX, Tao D, Niewiarowski PH, Tian Y, Liu Y, Dai L, Yang Y, Xia Z. Robust self-cleaning and micromanipulation capabilities of gecko spatulae and their bio-mimics. Nature communications. 2015 Nov 20; 6 .

[10] Chen H, Ruckenstein E. Structure and particle aggregation in block copolymer-binary nanoparticle composites. Polymer. 2010 Nov 12; 51(24): 5869-82.

[11] Kou BF, Liu QZ. Wetting Behavior of Hydrophobic Dust and Dust-Fall Theory of Fine Droplets. Brazilian Journal of Physics. 2015 Dec 1; 45(6): 708-12.

[12] Dang H, Singh VP, Guduru S, Rajaputra S, Chen ZD. Nanotube photovoltaic configuration for enhancement of carrier generation and collection. Nano Research. 2015 Oct 1; 8(10): 3186-96.

[13] Liu CY, Wang Q, Jia YZ, Zhang B, Jing R, Ma MZ, Jing Q, Liu RP. Effect of W particles on the properties of accumulatively roll-bonded $\mathrm{Al} / \mathrm{W}$ composites. Materials Science and Engineering: A. 2012 Jun 15; 547: 120-4.

[14] Feng YC, Geng L, Li AB, Zheng ZZ. Fabrication and characteristics of in situ Al12W particles reinforced aluminum matrix composites by reaction sintering. Materials \& Design. 2010 Feb 28; 31(2): 965-7. 
[15] Liu J, Su T, Wicks N, Pabon J, Bertoldi K. The Instability Mechanism of a Confined Rod Under Axial Vibrations. Journal of Applied Mechanics. 2016 Jan 1; 83(1): 011005.

[16] He J, Yuan FG. Damage identification for composite structures using a cross-correlation reverse-time migration technique. Structural Health Monitoring. 2015 Sep 11: 1475921715602546.

[17] Yang Y, Li X. Study on Ultrasonic Cavitation Based Solidification Processing and Nanoparticle Feeding for High Volume Fabrication of Aluminum Matrix Nanocomposites. In ASME 2005 International Mechanical Engineering Congress and Exposition 2005 Jan 1 (pp. 975-979). American Society of Mechanical Engineers.

[18] He J, Yuan FG. Lamb wave-based subwavelength damage imaging using the DORT-MUSIC technique in metallic plates. Structural Health Monitoring. 2016 Jan 7: 1475921715623359 .

[19] Gierlotka S, Palosz BF, Swiderska-Sroda A, Grzanka E, Kalisz G, Fietkiewicz K, Stelmakh S, Lathe C. Synthesis of metal-ceramic nanocomposites by high-pressure infiltration. InSolid State Phenomena 2004 Dec 1 (Vol. 101, pp. 157-164).

[20] Xu X, Park J, Hong YK, Lane AM. Magnetically self-assembled $\mathrm{SrFe}_{12} \mathrm{O}_{19} / \mathrm{Fe}-\mathrm{Co}$ core/shell particles. Materials Chemistry and Physics. 2015 Feb 15; 152: 9-12.

[21] $\mathrm{Gu} \mathrm{H}$, Wang J, Yu C. Three-dimensional Modeling of Percolation Behavior of Electrical Conductivity in Segregated Network Polymer Nanocomposites Using Monte Carlo Method. Advances in Materials. Vol. 5, No. 1, 2016, pp. 1-8.

[22] Cai W, Cui X, Zhou X. Optimization of a GPU Implementation of Multi-dimensional RF Pulse Design Algorithm. International Conference on Bioinformatics and Biomedical Engineering 2011.

[23] Feng YC, Geng L, Zheng PQ, Zheng ZZ, Wang GS. Fabrication and characteristic of Al-based hybrid composite reinforced with tungsten oxide particle and aluminum borate whisker by squeeze casting. Materials \& Design. 2008 Dec 31; 29(10): 2023-6.

[24] Wang L, Maruf SH, Maniglio D, Ding Y. Fabrication and characterizations of crosslinked porous polymer films with varying chemical compositions. Polymer. 2012 Aug 2; 53(17): 3749-55.

[25] Wang JJ, Lu GM, Yu JG. Numerical Analysis of Semi-Solid Die-Casting Automobile Part Based on the Thermo-Visco-Plastic Constitutive Relation. In Advanced Materials Research 2015 May 5 (Vol. 1096, pp. 268-274).

[26] Cai W, Gouveia LL. Modeling and Simulation of Maximum Power Point Tracker in Ptolemy. Journal of Clean Energy Technologies. 2013 Jan; 1(1).

[27] Shang SZ, Wang JJ, Lu GM, Zhang WN, Tang XL. Numerical simulation of thixo-diecasting Al6061 alloy automobile part. InAdvanced Materials Research 2011 Dec 6 (Vol. 418, pp. 1456-1459). Trans Tech Publications.

[28] Gu H, Gao XL, Li XC. Molecular Dynamics Study on Mechanical Properties and Interfacial Morphology of an Aluminum Matrix Nanocomposite Reinforced by $\beta$-Silicon Carbide Nanoparticles. Journal of Computational and Theoretical Nanoscience. 2009 Jan 1; 6(1): 61-72.
[29] Cai W, Shi F. $2.4 \mathrm{GHz}$ Heterodyne Receiver for Healthcare Application. International Journal of Pharmacy and Pharmaceutical Sciences, Vol 8 Issue 6, 2016.

[30] Wang S, Zhou Y, Tan J, Xu J, Yang J, Liu Y. Computational modeling of magnetic nanoparticle targeting to stent surface under high gradient field. Computational mechanics. $2014 \mathrm{Mar}$ $1 ; 53(3): 403-12$.

[31] Wang J, Shang S, Lu G, Yu J. Viscosity estimation of semi-solid alloys based on thermal simulation compression tests. International Journal of Materials Research. 2013 Mar 14; 104(3): 255-9.

[32] $\mathrm{Hu} \mathrm{Z,} \mathrm{Lu} \mathrm{W,} \mathrm{Thouless} \mathrm{MD,} \mathrm{Barber} \mathrm{JR.} \mathrm{Simulation} \mathrm{of} \mathrm{wear}$ evolution using fictitious eigenstrains. Tribology International. 2015 Feb 28; 82: 191-4.

[33] Zhang J, Liu K, Luo C, Chattopadhyay A. Crack initiation and fatigue life prediction on aluminum lug joints using statistical volume element-based multiscale modeling. Journal of Intelligent Material Systems and Structures. 2013 Nov 1; 24(17): 2097-109.

[34] Zhang J, Johnston J, Chattopadhyay A. Physics - based multiscale damage criterion for fatigue crack prediction in aluminium alloy. Fatigue \& Fracture of Engineering Materials \& Structures. 2014 Feb 1; 37(2): 119-31.

[35] Narayanunni V, Gu H, Yu C. Monte Carlo simulation for investigating influence of junction and nanofiber properties on electrical conductivity of segregated-network nanocomposites. Acta Materialia. 2011 Jun 30; 59 (11): 4548-55.

[36] Zhang J, Koo B, Subramanian N, Liu Y, Chattopadhyay A. An optimized cross-linked network model to simulate the linear elastic material response of a smart polymer. Journal of Intelligent Material Systems and Structures. 2015 Jul 21: 1045389X15595292.

[37] Zhang J, Koo B, Liu Y, Zou J, Chattopadhyay A, Dai L. A novel statistical spring-bead based network model for self-sensing smart polymer materials. Smart Materials and Structures. 2015 Jul 15; 24(8): 085022.

[38] Lennard-Jones JE. Cohesion. Proceedings of the Physical Society. 1931 Sep 1; 43(5): 461.

[39] Baskes MI. Modified embedded-atom potentials for cubic materials and impurities. Physical Review B. 1992 Aug 1; 46(5): 2727.

[40] Foiles SM, Baskes MI, Daw MS. Embedded-atom-method functions for the fcc metals $\mathrm{Cu}, \mathrm{Ag}, \mathrm{Au}, \mathrm{Ni}, \mathrm{Pd}, \mathrm{Pt}$, and their alloys. Physical Review B. 1986 Jun 15; 33(12): 7983.

[41] Li S, Arsenault RJ, Jena P. Quantum chemical study of adhesion at the $\mathrm{SiC} / \mathrm{Al}$ interface. Journal of applied physics. 1988 Dec 1; 64(11): 6246-53.

[42] Bermudez VM. Auger and electron energy - loss study of the $\mathrm{Al} / \mathrm{SiC}$ interface. Applied Physics Letters. 1983 Jan 1; 42(1): $70-2$.

[43] Li S, Arsenault RJ, Jena P. Quantum chemical study of adhesion at the $\mathrm{SiC} / \mathrm{Al}$ interface. Journal of applied physics. 1988 Dec 1; 64(11): 6246-53.

[44] Wang L, Ding Y. Creating micro-structured hydrogel-forming polymer films by photopolymerization in an evaporating solvent: Compositional and morphological evolutions. European Polymer Journal. 2015 May 31; 66: 99-107. 
[45] Cai W, Chan J, Garmire D. 3-Axes MEMS Hall-Effect Sensor. 2011 IEEE Sensors Applications Symposium, pp 141-144.

[46] Zhang, J. Multiscale Modeling of Heterogeneous Material Systems. Doctoral dissertation, Arizona State University. 2014.

[47] Liu Y, Huxtable ST, Yang B, Sumpter BG, Qiao R. Nonlocal thermal transport across embedded few-layer graphene sheets. Journal of Physics: Condensed Matter. 2014 Nov 13; 26(50): 502101 .
[48] $\mathrm{Hu} \mathrm{M}$, Hillyard P, Hartland GV, Kosel T, Perez-Juste J, Mulvaney P. Determination of the elastic constants of gold nanorods produced by seed mediated growth. Nano Letters. 2004 Dec 8; 4(12): 2493-7.

[49] Zhang, J, Gu, J, Li, L, Huan, Y and Wei, B. Bonding of alumina and metal using bulk metallic glass forming alloy. International Journal of Modern Physics B. 2009 Mar 20; 23(06n07): 1306-1312. 